\title{
Genome-based analysis for the identification of genes involved in o-xylene degradation in Rhodococcus opacus R7
}

\author{
Alessandra Di Canito ${ }^{1}$, Jessica Zampolli ${ }^{1}$, Alessandro Orro ${ }^{2}$, Pasqualina D'Ursi ${ }^{2}$, Luciano Milanesi ${ }^{2}$, Guido Sello ${ }^{3}$, \\ Alexander Steinbüchel ${ }^{4,5}$ and Patrizia Di Gennaro ${ }^{1 *}$
}

\begin{abstract}
Background: Bacteria belonging to the Rhodococcus genus play an important role in the degradation of many contaminants, including methylbenzenes. These bacteria, widely distributed in the environment, are known to be a powerhouse of numerous degradation functions, due to their ability to metabolize a wide range of organic molecules including aliphatic, aromatic, polycyclic aromatic compounds (PAHs), phenols, and nitriles. In accordance with their immense catabolic diversity, Rhodococcus spp. possess large and complex genomes, which contain a multiplicity of catabolic genes, a high genetic redundancy of biosynthetic pathways and a sophisticated regulatory network. The present study aimed to identify genes involved in the o-xylene degradation in R. opacus strain R7 through a genome-based approach.
\end{abstract}

Results: Using genome-based analysis we identified all the sequences in the R7 genome annotated as dioxygenases or monooxygenases/hydroxylases and clustered them into two different trees. The akb, phe and prm sequences were selected as genes encoding respectively for dioxygenases, phenol hydroxylases and monooxygenases and their putative involvement in o-xylene oxidation was evaluated. The involvement of the $a k b$ genes in o-xylene oxidation was demonstrated by RT-PCR/qPCR experiments after growth on o-xylene and by the selection of the R7-50 leaky mutant. Although the akb genes are specifically activated for o-xylene degradation, metabolic intermediates of the pathway suggested potential alternative oxidation steps, possibly through monooxygenation. This led us to further investigate the role of the prm and the phe genes. Results showed that these genes were transcribed in a constitutive manner, and that the activity of the Prm monooxygenase was able to transform o-xylene slowly in intermediates as 3,4-dimethylphenol and 2-methylbenzylalcohol. Moreover, the expression level of phe genes, homologous to the phe genes of Rhodococcus spp. 1CP and UPV-1 with a 90\% identity, could explain their role in the further oxidation of o-xylene and R7 growth on dimethylphenols.

Conclusions: These results suggest that R7 strain is able to degrade o-xylene by the Akb dioxygenase system leading to the production of the corresponding dihydrodiol. Likewise, the redundancy of sequences encoding for several monooxygenases/phenol hydroxylases, supports the involvement of other oxygenases converging in the o-xylene degradation pathway in R7 strain.

Keywords: Rhodococcus, Microbial genomics, o-xylene degradation, Gene clusters, Contaminated soil

\footnotetext{
* Correspondence: patrizia.digennaro@unimib.it

'Department of Biotechnology and Biosciences, University of Milano-Bicocca,

Piazza della Scienza 2, 20126 Milan, Italy

Full list of author information is available at the end of the article
}

(c) The Author(s). 2018 Open Access This article is distributed under the terms of the Creative Commons Attribution 4.0 International License (http://creativecommons.org/licenses/by/4.0/), which permits unrestricted use, distribution, and reproduction in any medium, provided you give appropriate credit to the original author(s) and the source, provide a link to the Creative Commons license, and indicate if changes were made. The Creative Commons Public Domain Dedication waiver (http://creativecommons.org/publicdomain/zero/1.0/) applies to the data made available in this article, unless otherwise stated. 


\section{Background}

Methylbenzenes are pollutants of great relevance for their toxic properties and their wide spread in environment, commonly present in crude petroleum and in various industrial processes [1]. Different methylbenzenes, including the three xylene isomers, can be degraded by several bacterial strains, with a degradation pathway that depends on the position of the methyl groups on the aromatic ring [2]. These bacteria can be divided into two groups: i) microorganisms that can degrade both $m$ - and $p$-xylene; and ii) microorganisms that can only degrade the ortho isomer. The two degradation pathways are rarely found simultaneously in the same microorganism.

Although bacteria capable of degrading $m$-xylene or $p$-xylene under aerobic conditions and their corresponding catabolic pathways have been well documented [3-5], bacteria capable of degrading $o$-xylene are not so common and their metabolic pathways have been poorly investigated [6-10]. Three $o$-xylene degradation pathways (leading to their corresponding catechols) have been reported [1, 8, 11-13] (Fig. 1). The first pathway is initiated by oxidation of the methyl group of $o$-xylene to form 2-methylbenzylalcohol, subsequently metabolized to form 3-methylcatechol as reported in the case of Rhodococcus sp. strain B3 [8] (Fig. 1, route A). The second degradation pathway of $o$-xylene is initiated by a ring-hydroxylating 2,3-dioxygenase leading to the 3,4-dimethylcatechol in
Rhodococcus sp. strain DK17 (Fig. 1, route B) [10]. While the third pathway is initiated by a ring-hydroxylating monooxygenase at the different position 3 , or 4 , as performed by the Toluene $o$-xylene Monooxygenase (ToMo) in P. stutzeri strain OX1 (Fig. 1, routes $\mathrm{C} 1$ and $\mathrm{C} 2$ ), leading to the formation of 3,4-dimethylcatechol [1].

One of the main roles in the degradation of many contaminants, including methylbenzenes, is played by bacteria belonging to the Rhodococcus genus. These bacteria, widely distributed in the environment, are characterized as a powerhouse of numerous degradation functions, since they are able to metabolize a wide range of organic molecules including aliphatic, aromatic and polycyclic aromatic compounds (PAHs), phenols, and nitriles [14]. In accordance with their immense catabolic diversity, Rhodococcus spp. are characterized to possess large and complex genomes, which contain a multiplicity of catabolic genes, a high gene redundancy of biosynthetic pathways and a sophisticated regulatory network [15]. Many of them also possess a variety of large linear plasmids and smaller circular plasmids that contribute to and also explain the immense repertoire of catabolic abilities [16]. The most known example is represented by the genome of Rhodococcus jostii strain RHA1 [17], isolated for its ability to aerobically degrade polychlorinated biphenyls (PCBs) [18], and also able to utilize a wide range of compounds as sole carbon and energy source.

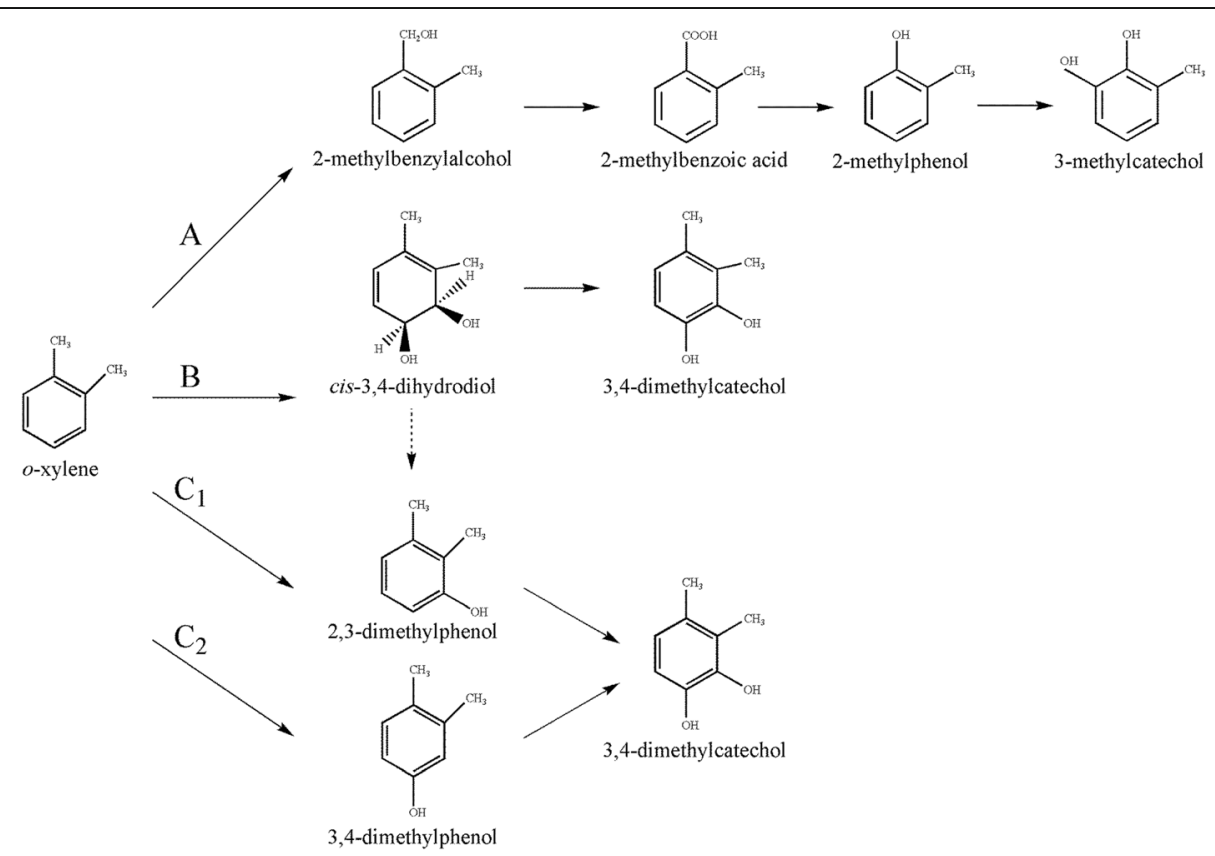

Fig. 1 Overview of different $O$-xylene degradation pathways in bacteria. Monooxygenation of the methyl group and subsequent oxidations in Rhodococcus sp. strain B3 (route A); dioxygenation and subsequent dehydrogenation of the aromatic ring in Rhodococcus sp. strain DK17 (route B); two successive monooxygenation reactions of the aromatic ring in P. stutzeri strain OX1 (route C1 and C2). Dashed arrow indicates a spontaneous dehydration 
Analyses of the $9.7 \mathrm{Mb}$ large genome of RHA1 provided the evidence of catabolic pathway redundancy and horizontal gene transfer events [17].

To date, several gene clusters involved in the degradation of multiple aromatic compounds have been identified from genome analysis of several Rhodococcus spp. strains, including genes for biphenyl [19], isopropylbenzene and ethylbenzene [20] and methylbenzenes [2]. However, few not in depth genetic studies have been reported regarding the abilities of Rhodococcus strains to degrade $o$-xylene. The only data regarding the genes involved in $o$-xylene degradation in bacteria belonging to Rhodococcus genus derives from the identification of the $a k b$ genes in Rhodococcus sp. strain DK17 [10]. This strain is able to grow on $o$-xylene (and toluene, ethylbenzene, isopropylbenzene) through a multicomponent $o$-xylene dioxygenase $[10,12]$. The DK17 o-xylene dioxygenase is described to perform a ring-oxidizing pathway leading to the 3,4-dimethylcathechol formation either by a dioxygenation or two monooxygenations, which can introduce two oxygen atoms successively. Thus, a deeper analysis concerning o-xylene degradation in Rhodococcus is necessary to understand which genes and enzymes could be involved in this metabolism.

In this context, the metabolically versatile Rhodococcus opacus R7 [21], known for its ability to grow on naphthalene, several long- and medium-chain $n$-alkanes, and aromatic hydrocarbons belonging to BTEX group (benzene, toluene, ethylbenzene and xylenes) [22, 23], and also able to grow on $o$-xylene, can be used to add information of the metabolism of this compound. The whole genome of R7 strain was completely sequenced and it revealed to possess multiple genes for the degradation of a large set of aliphatic, aromatic and PAHs compounds [24]. Moreover, the genome analysis revealed the presence, beside the chromosome, of five plasmids (pPDG1, pPDG2, pPDG3, pPDG4, pPDG5) that provided the evidence of high catabolic pathway redundancy.

Through a genome-based analysis, the present work aimed to identify genes and molecular mechanisms involved in $o$-xylene degradation in $R$. opacus R7. Based on the previous identification of 2,3-dimethylphenol (2,3-DMP) and 3,4-dimethylphenol (3,4-DMP) in the R7 culture medium and the fact that these intermediates were metabolized by R7 strain, when supplied as the sole carbon and energy source, we identified these compounds as intermediates of R7 $o$-xylene degradation pathway $[21,22]$. However, literature data suggested that the formation of dimethylphenol could be attributed to the dehydration of dihydrodiol deriving from the dioxygenation activity when $o$-xylene is supplied to Rhodococcus sp. strain DK17 [2]. For this reason, we searched and identified in the R7 genome all the sequences annotated as dioxygenases or monooxygenases/hydroxylases and clustered them into two different trees in order to select the oxygenases putatively involved in the $o$-xylene oxidation. Moreover, we demonstrated that the selected genes were involved in $o$-xylene degradation in $R$. opacus R7 by RT-PCR/qPCR, mutant analysis, cloning and expression experiments, thus revealing the complexity of this metabolic network.

\section{Results}

\section{R7 genome sequence analysis}

The formation of 2,3-dimethylphenol and 3,4-dimethylphenol (and the oxidation to 2-methylbenzylalcohol) in the R7 o-xylene degradation pathway [21, 22] suggests the involvement of monooxygenases able to oxidize $o$-xylene. However, the only $o$-xylene degradation pathway described in literature for bacteria of Rhodococcus genus is through the dioxygenase system of Rhodococcus sp. DK17 leading to the corresponding dihydrodiol that could be dehydrated to DMPs [2]. Therefore, we hypothesized that in the case of $R$. opacus strain R7 the formation of the identified intermediates could be explained by the involvement of different oxygenase systems for $o$-xylene degradation. For this reason, first we identified all the sequences annotated as dioxygenases or monooxygenases/ hydroxylases in the R7 genome and clustered them into two different trees in order to select all the oxygenases putatively involved in $o$-xylene oxidation.

\section{Analysis and clusterization of dioxygenases}

A preliminary genome RAST annotation of R7 allowed the identification of 83 potential dioxygenases. Among those, only 57 were selected as catalytic subunits of R7 dioxygenases. In order to cluster the R7 catalytic subunits, 22 reference sequences putatively involved in the aromatic compound degradation were considered. The generated tree reveals that these amino acid sequences are divided into eight clades (Fig. 2). All the sequences are listed in Additional file 1: Table S1, including the reference sequences with the relative source strain and all the sequences belonging to R7 strain.

Clade number 3 includes dioxygenases putatively involved in the upper pathways of BTEX compounds and polycyclic aromatic hydrocarbons (Fig. 2, blue box), while the other seven clades include all the dioxygenases putatively involved in the peripheral pathways of different aromatic compounds (Fig. 2).

Among the sequences in clade number 3 of the dioxygenase-tree (Fig. 2, extended clade), the catalytic subunit of ethylbenzene dioxygenase (EtbAa1) of $R$. jostii RHA1 [25] and the $o$-xylene dioxygenase (AkbA1a) of Rhodococcus sp. DK17 [10], are shown to cluster near the only homologous dioxygenase sequence (AkbAla) of R7. Multiple alignments of AkbA1a of R7 with proteins belonging to Bacterial Rieske non-heme iron oxygenases 


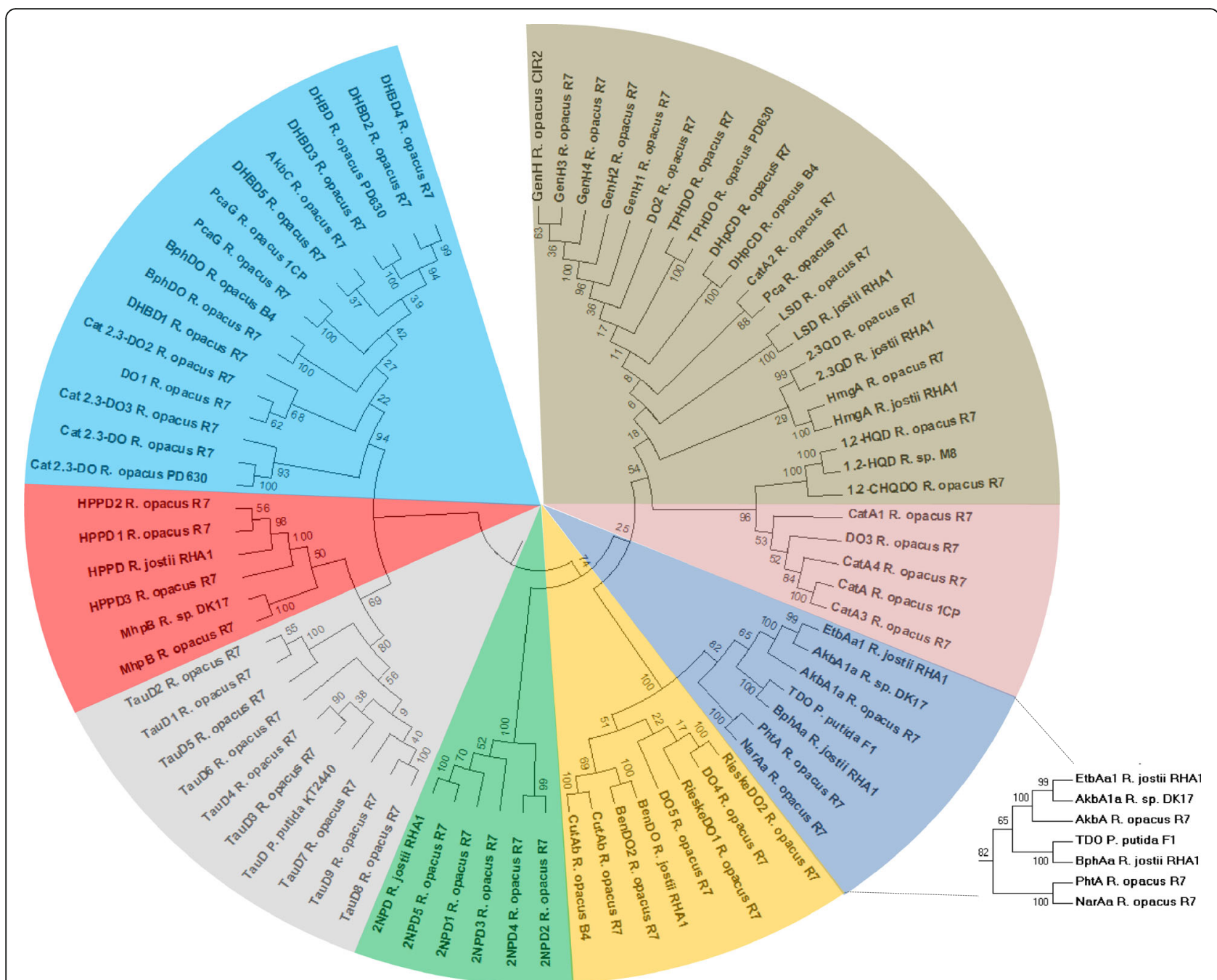

Fig. 2 Phylogenetic tree of R. opacus R7 proteins containing the catalytic subunit of dioxygenases. The tree was constructed aligning selected reference protein sequences with R7 sequences. Numbers represent the bootstrap values on the branches calculated for maximum likelihood (ML) method selected from the package MEGA version 6 with 100 bootstraps. Color scheme for dioxygenases: brown, clade 1; pink, clade 2; blue, clade 3; yellow, clade 4; green, clade 5; grey, clade 6; red, clade 7; light blue, clade 8. The extended clade includes the AkbA1a of R. opacus R7 homologous to the AkbA1a of $R$. sp. DK17 involved in the oxidation of o-xylene. Abbreviation of dioxygenase names are reported in Additional file 1: Table S1

reveals the coordination of the center iron-sulfur (Fe-S) $(\mathrm{CxH}-\mathrm{CxxH})$ with the amino acids that coordinate the iron atom of the active site $(\mathrm{H}-\mathrm{H}-\mathrm{D})$. Moreover, the $a k b A 1 a$ gene encoding for the AkbA1a dioxygenase shows a nucleotide identity around $90 \%$ with the etbAal of $R$. jostii RHA1 and akbA1a of Rhodococcus sp. DK17. For these features, the AkbAla was taken into consideration for its involvement in $o$-xylene catabolism.

The remaining clades of the tree analysis include several dioxygenases involved in the mechanism of aromatic ring cleavage (e. g. gentisate 1,2-dioxygenases, catechol 1,2-dioxygenases, catechol 2,3-dioxygenases, homogentisate dioxygenase and protocatechuate dioxygenase), that are not taken into consideration.

\section{Analysis and clusterization of monooxygenases/hydroxylases}

From all the sequences derived from the whole genome of R7, the attention was also focused on putative sequences annotated as monooxygenases/hydroxylases. Then, a multiple amino acidic sequence alignment and a clusterization analysis were performed to predict protein functions using characterized monooxygenases/hydroxylases from different bacteria as reference (Fig. 3). All the sequences are listed in Additional file 2: Table S2, including the reference sequences with the relative source strain and all the sequences belonging to the R7 strain. The sequences obtained by this analysis are clustered into 10 clades. Clade number 1 includes the phenol hydroxylases P164, P165, P166, P167, P149 and P150 used as reference 


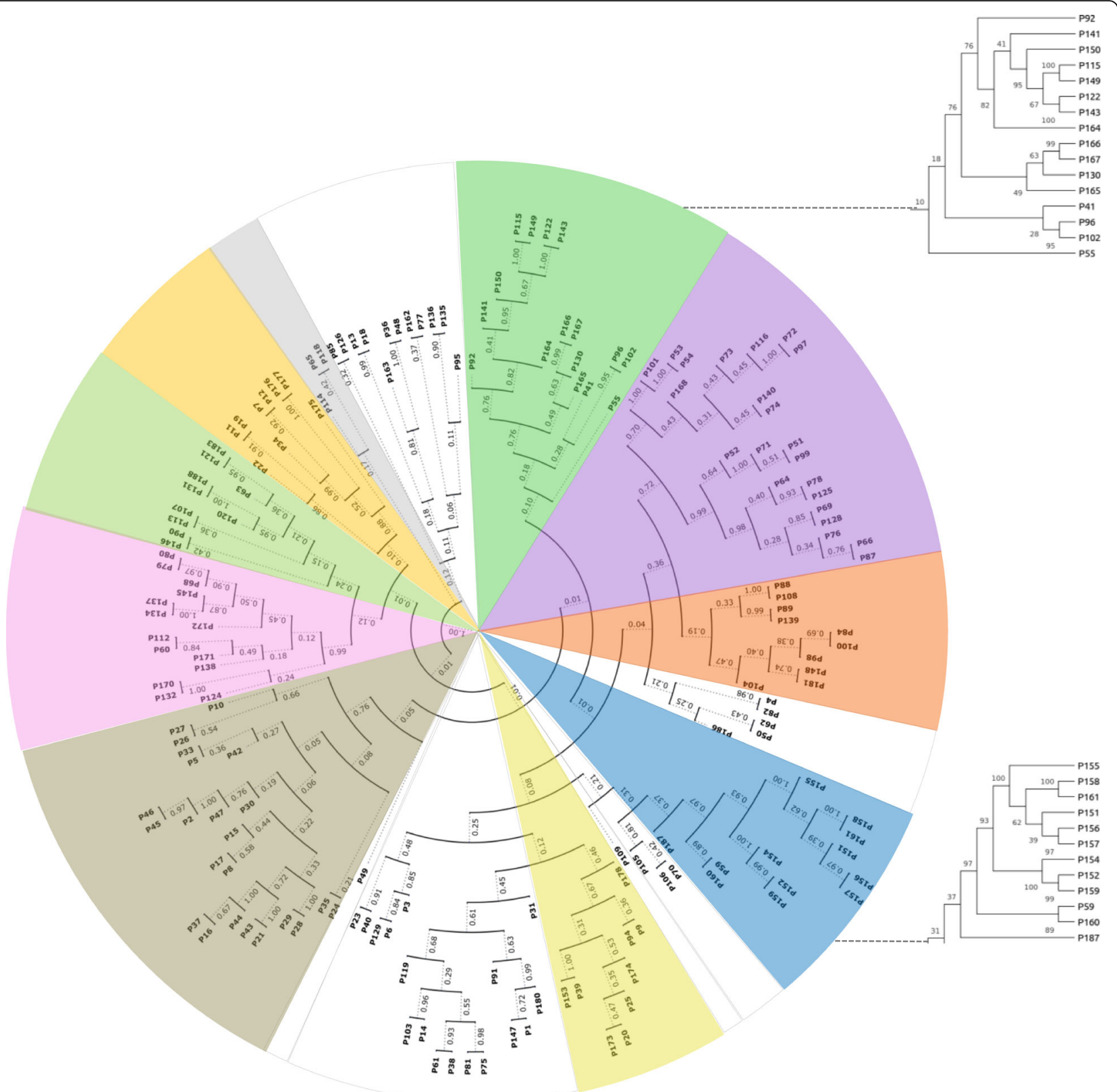

Fig. 3 Phylogenetic tree of R. opacus R7 proteins containing the catalytic subunit of hydroxylases and monooxygenases. The tree was constructed aligning selected reference protein sequences with R7 sequences. Numbers represent the bootstrap values on the branches calculated for maximum likelihood (ML) method selected from the package MEGA version 6 with 100 bootstraps. Distinct clades are labeled with different colors: green, clade 1; purple, clade 2; red, clade 3; blue, clade 4; yellow, clade 5; brown, clade 6; pink, clade 7; light green, clade 8; orange, clade 9; grey, clade 10. White clades surrounded by grey lines correspond to not classified proteins: clade of not classified protein 1-6. The extended clade 1 includes the R7 proteins PheA1a, PheA2a, PheA3a; the extended clade 4 includes the R7 PrmA protein. The tree image was built with the ETE Toolkit using the circular plot function, with equal branch lengths and labeling each node with bootstrap support. Abbreviation of hydroxylase and monooxygenase names are reported in Additional file 2: Table S2

sequences. Amongst these sequences, solely the P149 of $R$. opacus 1CP [26] was found to be similar to P115 (PheA1a) (98\%), P122 (PheA2a) (92\%), and P143 (PheA3a) (92\%) of R. opacus R7. Accordingly, from this clade we selected the P115, P122 and P143 sequences (encoded by the pheA1a gene, pheA2a gene, and pheA3a gene, respectively) for further molecular analysis.

In clade number 4, only the P59 (PrmA) (encoded by the prmA gene) of R7, annotated as alpha chain methane monooxygenase component, is shown to cluster with all 
the phenol hydroxylases/monooxygenases used as reference sequences. Among the reference sequences, the TouA component (P151) of Toluene $o$-xylene Monooxygenase (ToMo) and the $\mathrm{PhN}$ component (P152) of Phenol Hydroxylase $(\mathrm{PH})$ from $P$. stutzeri OX1, were mainly considered because they are the most described in literature for $o$-xylene oxidation [27-30]. In fact, comparing the amino acid sequences of the TouA component (P151) of ToMo, the PhN component (P152) of PH, and of PrmA (P59), the most residues of the catalytic site of the three proteins were found to be conserved. Thus, P59 was selected to investigate its involvement in $o$-xylene degradation.

R7 proteins of clades number 2, 3 and 5, 6 including cyclohexanone monooxygenases [31], FAD-dependent monooxygenases [32], salicylate hydroxylases [33], and putative P450 hydroxylases respectively [34], were excluded from further molecular analysis in this paper, as little is known regarding their putative involvement in $o$-xylene oxidation.

Regarding the other clades number 7, 8, 9, 10 including, respectively, putative nitrilotriacetate monooxygenases [35], alkanesulfonate monooxygenases [36], other putative monooxygenases/hydroxylases, and ubiquinone monooxygenases [37], we excluded their involvement in the hydroxylation/monooxygenation of $o$-xylene, because their function seems to be very distant from our search.

Moreover, the proteins of the non-classified clades 1-6 were excluded because they were lacking in reference sequences.

\section{Involvement of the $a k b$ genes in o-xylene degradation by RT-PCR experiments}

Analyses of the R7 genome sequences evidenced the presence of the $a k b A 1 a$ gene in the $a k b$ gene cluster allocated on the megaplasmid pPDG5 (Table 1). This gene, coding for a large subunit dioxygenase component (AkbA1a), clustered with the following: the $a k b A 2 a$ gene coding for a small subunit dioxygenase component (AkbA2a), the $a k b A 3$ gene for a ferredoxin component (AkbA3), the HP sequence for an hypothetical protein (HP) of unknown function, the $a k b A 4$ gene for a reductase component (AkbA4), and the $a k b B$ gene coding for a dihydrodiol dehydrogenase (AkbB) (Fig. 4, panel a). Downstream (in the opposite direction) of these sequences, we found two sequences homologous (near the 80\%) to the $a k b S$ and $a k b T$ sequences encoding for the sensor and regulator elements of DK17 strain, potentially involved in the regulatory mechanism.

Moreover, we found a second group of genes ( $a \mathrm{k} b C D E F$ genes) coding for complete meta-cleavage enzymes of the lower pathway allocated on the pPDG2 plasmid, including: a meta-cleavage dioxygenase (AkbC), a meta-cleavage hydrolase (AkbD), an hydratase component (AkbE), and an aldolase $(\mathrm{AkbF})$, respectively.

The involvement of the $a k b$ genes in the $o$-xylene degradation of R7 strain was analyzed by RT-PCR experiments. For this, RT-PCR were performed with RNA derived from $R$. opacus $\mathrm{R} 7$ cells grown in presence of $o$-xylene, or 2,3-DMP, or toluene, or malate as control. Separate cDNA synthesis reactions were performed and cDNA was then amplified with primer pairs used to amplify the target genes. The target genes were $a k b A 1 A 2 a$ coding for the small and the large components of the dioxygenase, or $a k b B$ coding for the dihydrodiol dehydrogenase, or $a k b C$ coding for the meta-cleavage dioxygenase. RT-PCR analysis showed that the $a k b A 1 A 2 a, a k b B$, and $a k b C$ genes were transcribed in $\mathrm{R} 7$ cells after growth on $o$-xylene (or toluene) (Fig. 5, panel a). These results indicate that $o$-xylene induced the transcription of the $a k b$ genes, suggesting the involvement of a dioxygenation route for R7 o-xylene degradation. But, as described above, the analyses of intermediates revealed that 2,3-dimethylphenol and 3,4-dimethylphenol were non-inducers of the pathway. Indeed, RT-PCR experiments with the same $a k b A 1 A 2 a, a k b B$, and $a k b C$ genes, after growth in presence of 2,3-dimethylphenol and 3,4-dimethylphenol, did not show any amplification. This propelled us in the direction to search in the R7 genome for other sequences encoding for monooxygenases/hydroxylases and to demonstrate their subsequent involvement in alternative pathways for $o$-xylene degradation leading to dimethylphenols.

Involvement of the $a k b$ genes in o-xylene degradation by the identification of $R$. opacus R7 mutants in this cluster

Random mutagenesis performed after electroporation of R7 cells with the pTNR vector generated mutants of R7 unable to growth on $o$-xylene.

We investigated the growth phenotypes and substrate transforming capabilities of R7 mutants by the transposon insertion detection. Among the single transposed mutant, the clearest phenotype was observed in the R7-50 mutant strain, in which the mutation was constituted by the insertion of the transposon in the $a k b S$ gene (Fig. 4, dashed box). This strain was considered a leaky mutant for the growth on 0 -xylene, as it is reported in Fig. 6 (panel a growth on malate, panel B growth on $o$-xylene) in comparison to the R7 wild type strain. In fact, Fig. 6 displays a lower rate of growth for the mutant in respect to the wild type strain when grown on $o$-xylene, while there is a similar trend when both strains are grown on malate.

These data are in accordance with what was observed by Kim et al. [38] when the ATP-binding motif of the sensor $a k b S$ gene was mutated in the DK17 strain. The mutation in the $a k b S$ gene allowed the incapacity of DK17 strain to grow well on $o$-xylene. So, our results 
Table 1 List of the identified genes

\begin{tabular}{|c|c|c|c|c|c|c|c|}
\hline Gene name & $\begin{array}{l}\text { Protein } \\
\text { name }\end{array}$ & $\begin{array}{l}\text { Homologous } \\
\text { protein }\end{array}$ & Bacterium & aa Identity & Function & $\begin{array}{l}\text { Accession } \\
\text { number }\end{array}$ & Reference \\
\hline$a k b B(813 \mathrm{bp})$ & AkbB & AkbB & R. sp. DK17 & $85 \%$ & Dihydrodiol dehydrogenase & All1 1489.1 & Kim et al., 2004 \\
\hline akbA4 (1263 bp) & AkbA4 & AkbA4 & R. sp. DK17 & $81 \%$ & Ferredoxin reductase & All11490.1 & Kim et al., 2004 \\
\hline akbA3 (150 bp) & AkbA3 & AkbA3 & R. sp. DK17 & $69 \%$ & Ethylbenzene dioxygenase ferredoxin & СР008952.1 & Kim et al., 2004 \\
\hline akbA2a (549 bp) & AkbA2a & AkbA2a & R. sp. DK17 & $84 \%$ & Ethylbenzene dioxygenase small subunit & All1 1492.1 & Kim et al., 2004 \\
\hline akbA1a (1323 bp) & AkbA1a & AkbA1a & R. sp. DK17 & $92 \%$ & Ethylbenzene dioxygenase large subunit & All1 1493.1 & Kim et al., 2004 \\
\hline akbs (4812 bp) & Akbs & Akbs & R. sp. DK17 & $76 \%$ & Sensor kinase & All1 1494.1 & Kim et al., 2004 \\
\hline akbT (534 bp) & AkbT & AkbT & R. sp. DK17 & $86 \%$ & Response regulator & All1 1495.1 & Kim et al., 2004 \\
\hline$a k b F(762$ bp) & AkbF & AkbF & R. sp. DK17 & $63 \%$ & 4-Hydroxy-2-oxovalerate aldolase & All1 1049.1 & Kim et al., 2004 \\
\hline akbE (900 bp) & AkbE & AkbE & R. sp. DK17 & $64 \%$ & 2-Hydroxypenta-2,4-dienoate hydratase & All11050.1 & Kim et al., 2004 \\
\hline$a k b D(858 \mathrm{bp})$ & AkbD & AkbD & R. sp. DK17 & $67 \%$ & $\begin{array}{l}\text { 2-Hydroxy-6-oxo-6-phenylhexa-2,4-dienoate } \\
\text { hydrolase }\end{array}$ & All1 1051.1 & Kim et al., 2004 \\
\hline$a k b C(900 \mathrm{bp})$ & AkbC & AkbC & R. sp. DK17 & $87 \%$ & 2,3-Dihydroxybiphenyl 1,2-dioxygenase & All1 1058.1 & Kim et al., 2004 \\
\hline pheA1a (1617 bp) & PheA1a & $\begin{array}{l}\text { PheA1 (1) } \\
\text { PheA1 (2) } \\
\text { PheA1 (3) }\end{array}$ & R. opacus $1 \mathrm{CP}$ & $\begin{array}{l}83 \% \\
93 \% \\
98 \%\end{array}$ & Phenol hydroxylase & All08653.1 & Gröning et al., 2014 \\
\hline pheA1b (573 bp) & PheA1b & $\begin{array}{l}\text { PheA2 (1) } \\
\text { PheA2 (2) } \\
\text { PheA2 (3) }\end{array}$ & R. opacus $1 \mathrm{CP}$ & $\begin{array}{l}73 \% \\
100 \% \\
74 \%\end{array}$ & Phenol hydroxylase reductase component & All08654.1 & Gröning et al., 2014 \\
\hline pheA2a (1617 bp) & PheA2a & $\begin{array}{l}\text { PheA1 (1) } \\
\text { PheA1 (2) } \\
\text { PheA1 (3) }\end{array}$ & R. opacus $1 \mathrm{CP}$ & $\begin{array}{l}83 \% \\
100 \% \\
92 \%\end{array}$ & Phenol hydroxylase & All08806.1 & Gröning et al., 2014 \\
\hline pheA2b (561 bp) & PheA2b & $\begin{array}{l}\text { PheA2 (1) } \\
\text { PheA2 (2) } \\
\text { PheA2 (3) }\end{array}$ & R. opacus $1 \mathrm{CP}$ & $\begin{array}{l}69 \% \\
75 \% \\
94 \%\end{array}$ & Phenol hydroxylase reductase component & All08807.1 & Gröning et al., 2014 \\
\hline pheA3a (1617 bp) & PheA3a & $\begin{array}{l}\text { PheA1 (1) } \\
\text { PheA1 (2) } \\
\text { PheA1 (3) }\end{array}$ & R. opacus 1CP & $\begin{array}{l}83 \% \\
97 \% \\
91 \%\end{array}$ & Phenol hydroxylase & All10865.1 & Gröning et al., 2014 \\
\hline pheA3b (654 bp) & PheA3b & $\begin{array}{l}\text { PheA2 (1) } \\
\text { PheA2 (2) } \\
\text { PheA2 (3) }\end{array}$ & R. opacus $1 \mathrm{CP}$ & $\begin{array}{l}61 \% \\
64 \% \\
58 \%\end{array}$ & Phenol hydroxylase reductase component & СР008949.1 & Gröning et al., 2014 \\
\hline prmA (1635 bp) & PrmA & PrmA & R. jostii RHA1 & $97 \%$ & $\begin{array}{l}\text { Methane monooxygenase component A } \\
\text { alpha chain }\end{array}$ & All03499.1 & Sharp et al., 2007 \\
\hline prmC (1044 bp) & PrmC & PrmC & R. jostii RHA1 & $94 \%$ & Methane monooxygenase component $C$ & All03498.1 & Sharp et al., 2007 \\
\hline prmB (1107 bp) & PrmB & PrmB & R. jostii RHA1 & $97 \%$ & $\begin{array}{l}\text { Methane monooxygenase component } \\
\text { A beta chain }\end{array}$ & All03497.1 & Sharp et al., 2007 \\
\hline prmD (342 bp) & PrmD & PrmD & R. jostii RHA1 & $98 \%$ & $\begin{array}{l}\text { Methane monooxygenase regulatory } \\
\text { protein }\end{array}$ & All03496.1 & Sharp et al., 2007 \\
\hline
\end{tabular}

indicate that $a k b S$ is necessary for the growth on $o-\mathrm{xy}$ lene also in the R7 strain. Moreover, these data confirm the results of RT-PCR and suggest the kind of regulation involved in the $o$-xylene degradation pathway in the R7 strain. Indeed, this degradation process is likely mediated by the system sensor-regulator AkbS-AkbT through the binding of $o$-xylene.

\section{Identification of the involvement of the phe genes and the prm genes in o-xylene degradation by RT-PCR experiments}

Based on the identified sequences from genome analysis and the previous metabolic intermediates of R7 $o$-xylene degradation pathway, we analyzed the involvement of some putative sequences encoding for monooxygenases/ phenol hydroxylases in this pathway. In particular, we selected the sequences deriving from clade number 1 (called phe sequences) and the sequences from clade number 4 (called prm sequences) (Table 1). We identified a first phe sequence (pheA1a) encoding for the monooxygenase PheA1a (P115) that showed a nucleotide identity of $98 \%$ with the sequences of the pheA1(3) gene of $R$. opacus 1CP, involved in the phenol hydroxylation [26]. In the R7 genome, this gene (pheA1a) clustered with another gene (pheA1b) encoding for a phenol hydroxylase-reductase component and other open reading frames (ORFs) encoding for unknown functions (Fig. 4, panel b). From the same group of sequences, we also selected other two sequences, pheA2a (PheA2a) (P122) homologous to the pheA1(2) gene 
A

pPDG5
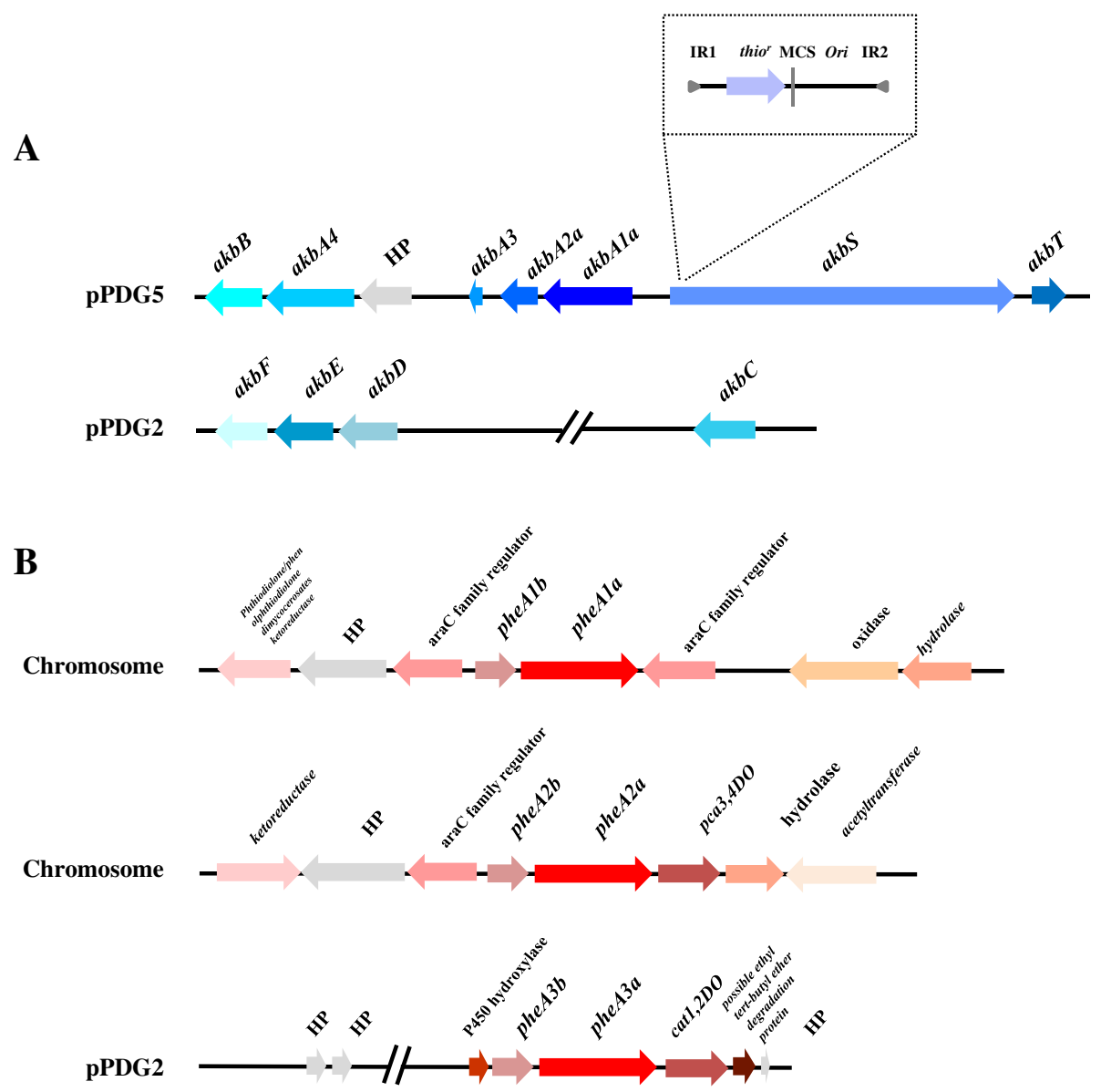

C

Chromosome

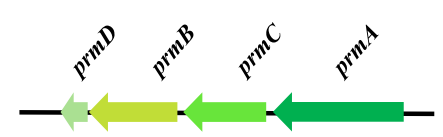

$1 \mathrm{~kb}$

Fig. 4 Genetic organization of the akb, phe, and prm genes in R. opacus R7. a On pPDG2 plasmid: akbAla, large subunit of o-xylene dioxygenase; $a k b A 2 a$, small subunit of o-xylene dioxygenase; $a k b A 3$, ferredoxin component; $a k b A 4$, reductase component; akbB, dihydrodiol dehydrogenase; $a k b S$, sensor kinase; and $a k b T$, response regulator. On pPDG5 plasmid: akbC, meta-cleavage dioxygenase, akbD, meta-cleavage hydrolase product, $a k b E$, hydratase and $a k b F$, aldolase. Dashed box reported the IS1415 insertion deriving from the transposon mutagenesis and dashed lines localized the insertion element within the akbS gene of R7. b Three phe gene clusters: pheA1a (P115), phenol hydroxylase, and pheA1b, phenol hydroxylase-reductase component located on the chromosome; pheA2a (P122), phenol hydroxylase, and pheA2b, phenol hydroxylase-reductase component located on the chromosome; pheA3a (P143), phenol hydroxylase, and pheA3b, phenol hydroxylase-reductase component located on the pPDG2 plasmid. c prm gene cluster located on the chromosome: prmA (P59), large hydroxylase subunit of a monooxygenase, prmC, small hydroxylase subunit of a monooxygenase, prmB, reductase component, and prmD, regulatory coupling protein. Genes with unknown or hypothetical functions were reported as HP. Identified genes (listed in Table 1) and their orientation are shown by arrow

(99\%) of R. opacus $1 \mathrm{CP}$ and pheA3a (PheA3a) (P143) homologous to the pheA1(2) gene (97\%) of $R$. opacus $1 \mathrm{CP}$. The pheA2a gene clustered with the pheA2b gene coding for a phenol hydroxylase-reductase component and a pca 3,4-dioxygenase; while the pheA3a gene clustered with the phe $A 3 b$ gene coding for a phenol hydroxylase-reductase component and a catechol 1,2 dioxygenase. The last phe gene cluster was found allocated on the PPDG2 plasmid.
We performed RT-PCR experiments on these identified sequences after growth of R7 cells in presence of $o$-xylene, or toluene, or 2,3-DMP, or malate as control. Separate cDNA synthesis reactions were performed and cDNA was then amplified with primer pairs used to amplify the target genes. RT-PCR analysis showed that in R7 cells grown on $o$-xylene (or on toluene), both the pheAla gene (P115) and the pheA3a gene (P143) were amplified as well as on malate (Fig. 5, panel b). Among 

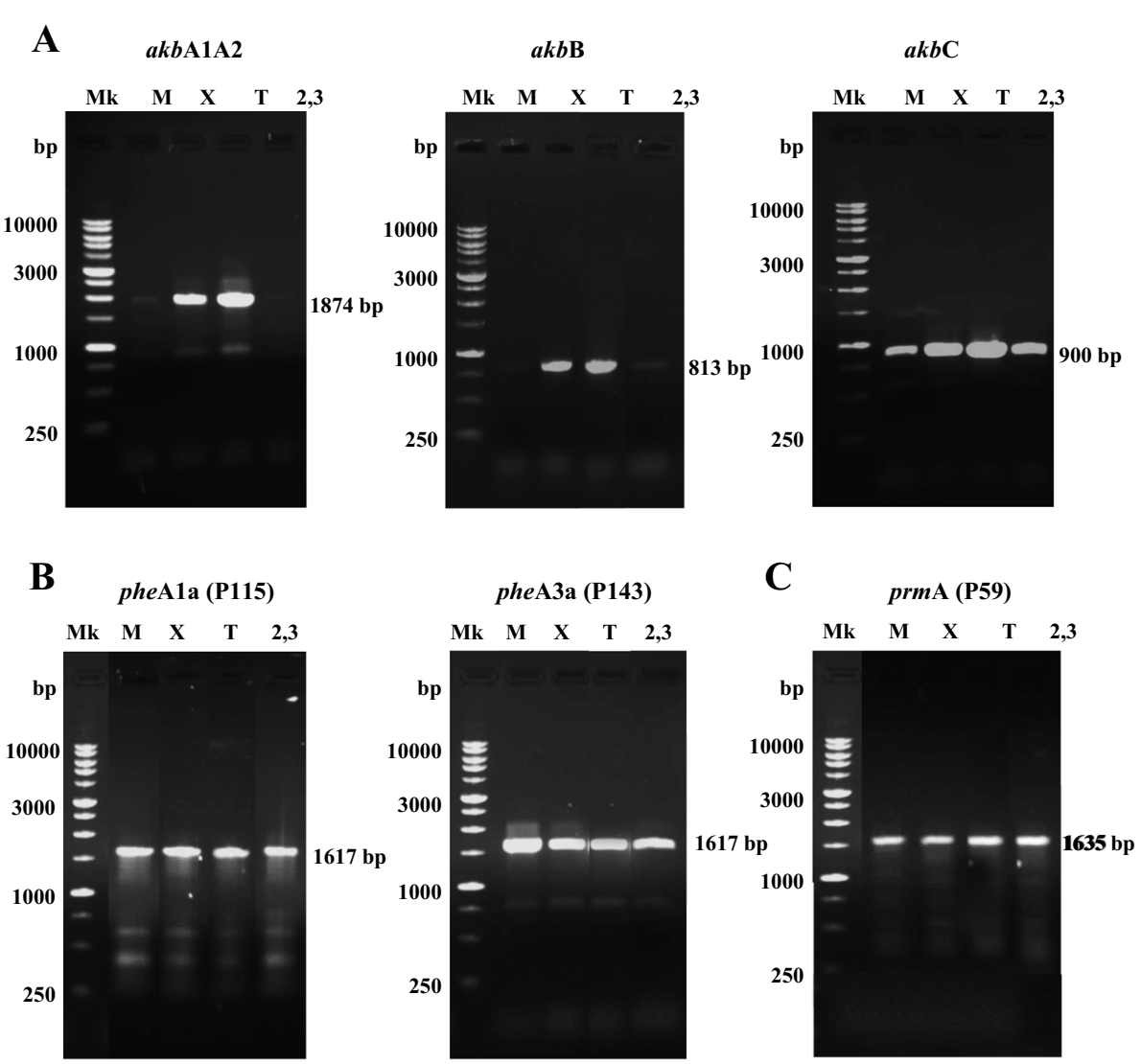

Fig. 5 RT-PCR experiments from RNA extracted from R. opacus R7. RT-PCR experiments with akbA1A2, akbB and akbC genes (a); RT-PCR experiments with pheA1a, pheA3a (b), and with prmA genes (c). M 100 to 10,000-bp markers, M growth on mineral medium M9 and malate used as control, $X$ growth on o-xylene, T growth on toluene, 2,3 growth on 2,3-dimethylphenol

the identified phe sequences, the pheA2a sequence (P122) was not tested because we decided to test only the main representatives pheA1a (P115) and pheA3a (P143) as they are allocated on the chromosome and on the pPDG2 plasmid, respectively.

Moreover, as R7 strain was also able to oxidize $o$-xylene leading to the corresponding 2-methylbenzylalcohol, and data on RHA1 strain indicated the presence of genes up-regulated on propane coding for components of ethylbenzene dioxygenase [39], we decided to include the prm genes in the analysis (Fig. 4, panel c). The prm genes were found in a cluster constituted by the prm $A, C, B, D$ genes, allocated on the chromosome with a percentage of amino acid identity near the $90 \%$ with the corresponding gene products of RHA1 strain. The prmA gene and prmC gene coded the large hydroxylase and the small hydroxylase subunits of a monooxygenase (annotated as propane monooxygenase), as $\mathrm{prmB}$ for

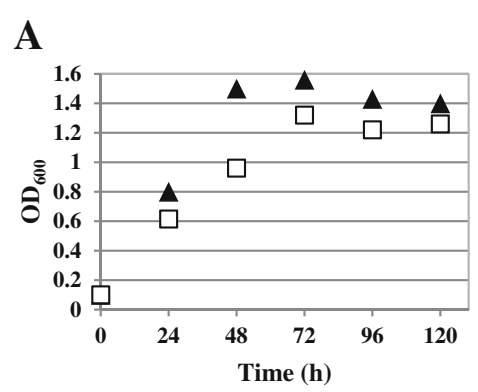

B
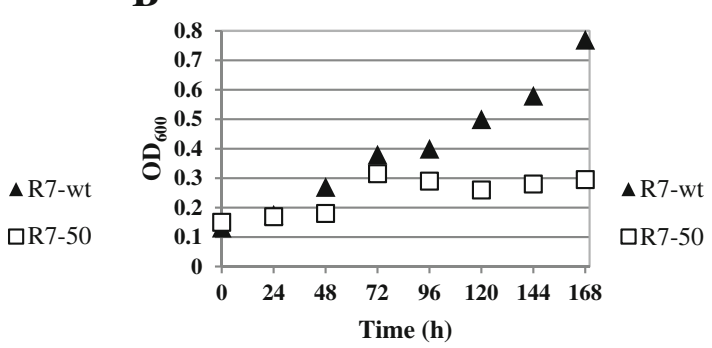

Fig. 6 Growth curves on o-xylene in wild type R. opacus R7 and R7-50 mutant strain. Cells were grown in presence of M9 mineral medium and malate (a) or M9 mineral medium supplied in an atmosphere saturated with o-xylene (b) 
the reductase component and prmD for the regulatory coupling protein, respectively.

Also concerning these genes, we tested their involvement in $o$-xylene degradation by expression of the $\mathrm{prm} A$ gene (P59) in presence of the same substrates reported above for phe genes (Fig. 5, panel c). This gene was expressed in the presence of $o$-xylene as well as on malate, toluene and DMPs. These results indicated that the prm genes were amplified similarly to the phe genes, suggesting that they could work even when the strain was in absence of the hydrocarbon or phenols. Moreover, the gene redundancy of several monooxygenases/phenol hydroxylases supported the hypothesis of alternative pathways for $o$-xylene degradation in R7 strain. At the same time, the amplification of the PrmA (P59) could explain the formation of the corresponding 2-methylbenzyalcohol.

\section{Quantitative real-time RT-PCR (qPCR) analysis}

Quantitative real-time reverse transcription-PCR (qPCR) experiments were performed to quantify the levels of transcription of akbA1a (AkbA1a), prmA (P59) and pheA1a (P115) genes of R7 strain, representative of the selected catalytic subunit of different oxygenase systems putatively involved in $o$-xylene oxidation. qPCR experiments were performed after growth of R7 cells in presence of $o$-xylene, toluene and 2,3-DMP or malate as control. The values of transcription after R7 malate-grown cells were used as a basal level for comparison with the quantities determined with the substrates of interest. The level of $a k b A l a$ gene was approximately $19 \pm 7.5$-fold higher after growth on $o$-xylene (with a similar trend on toluene) than on malate. On the other hand, this analysis confirms that prmA and pheA1a gene transcription levels increased much less, which probably reflects their constitutive expression. In fact, the transcription levels of $a k b A 1 a$ gene in respect to prmA and pheAla genes after growth on $o$-xylene (and on toluene), were found to be significantly different, with respective values of $0.23 \pm 0.04$ and $0.44 \pm 0.11$ (Table 2). A different trend was observed for the expression of the prmA and the pheAla genes (akbAla gene was not tested as it was not amplified in RT-PCR) after growth on 2,3-DMP. In this case, results showed an increase of the pheA1a transcription levels $5.18 \pm 0.91$-fold higher after growth on the corresponding dimethylphenol, whereas prmA was not induced.
These results demonstrated that $o$-xylene was able to activate mainly the transcription of the akbAla gene whilst a very low level of the other two genes during the aerobic growth of R7 cells on $o$-xylene. Meanwhile, in presence of 2,3-DMP a higher level of expression of phenol hydroxylase was observed.

\section{Involvement of the prm genes by cloning and expression of the activity in $R$. erythropolis AP}

In order to evaluate the role of the prmACBD gene cluster in the $o$-xylene metabolism, the region of $4.3 \mathrm{~kb}$ was isolated from R7 genomic DNA as NdeI/HindIII fragment. The PCR product was cloned into the shuttle-vector $E$. coli-Rhodococcus pTipQC2 to obtain pTipQC2-prmACBD-R7.

The recombinant plasmid pTipQC2-prmACBD-R7 was isolated from $E$. coli DH5a and transferred by electroporation into Rhodococcus erythropolis AP, which was not able to use the $o$-xylene as only carbon and energy source. The prmACBD gene cluster was expressed under the inducible thiostrepton promoter (PtipA) through experiments with resting cells of $R$. erythropolis AP (pTipQC2-prmACBD-R7) exposed to $o$-xylene to identify the metabolites. The activity of the recombinant strain was compared to the activity of wild type AP strain treated in the same conditions as control. $R$. erythropolis AP (pTipQC2-prmACBD-R7) cells, which were pre-grown on $\mathrm{LB}$ and washed in mineral medium M9, were exposed to $o$-xylene dissolved in isoctan in a biphasic system. The water phase was analyzed at different incubation times by reverse-HPLC analysis; 3,4-dimethylphenol and 2-methylbenzylalcohol were identified by comparison with reference compounds (standard mixture) (Fig. 7). These compounds were observed in the first $2 \mathrm{~h}$ of exposure, then they were progressively metabolized and disappeared after $6 \mathrm{~h}$. It was not possible to confirm the formation of the 2,3-dimethylphenol. None of these metabolites was identified in the wild type host strain. These results suggested that the prmACBD gene cluster could have a role within the $o$-xylene metabolism, in particular in the first step of oxidation.

\section{Discussion}

The genome-based analysis of $R$. opacus strain R7 revealed a considerable multiplicity of genes potentially involved in $o$-xylene catabolism. Although much is known about the

Table 2 qPCR analysis. Relative gene expression of R. opacus R7 grown on o-xylene, toluene and 2,3-dimethylphenol (2,3-DMP)

\begin{tabular}{|c|c|c|c|c|c|c|}
\hline \multirow[t]{2}{*}{ Substrate } & \multicolumn{6}{|c|}{ Normalized genes amount relative to malate condition $\left(2^{-\Delta \Delta c t}\right)$} \\
\hline & $a k b A 1 a$ & & prmA & & pheAl & \\
\hline o-xylene & 19.14 & \pm 7.55 & 0.23 & \pm 0.04 & 0.44 & \pm 0.11 \\
\hline toluene & 15.14 & \pm 6.56 & 1.53 & \pm 0.39 & 2.14 & \pm 0.65 \\
\hline 2,3-DMP & - & - & 0.04 & \pm 0.01 & 5.18 & \pm 0.91 \\
\hline
\end{tabular}

Values are means of three replicates \pm standard deviation 


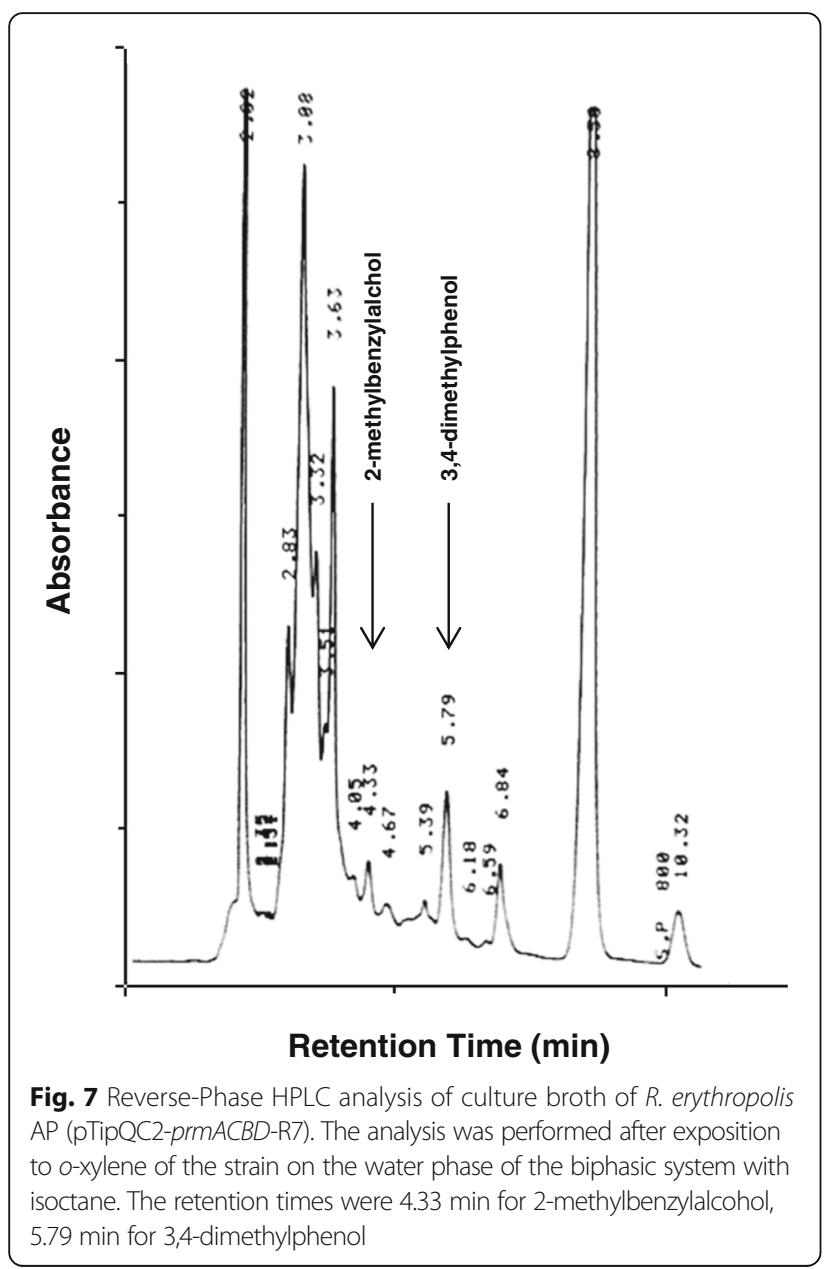

ability of Rhodococcus strains to grow on toluene and ethylbenzene [39-41], little is known about the catabolism of $o$-xylene in bacteria belonging to the Rhodococcus genus [11]. $R$. opacus R7 is a strain isolated for its ability to grow on $o$-xylene as the only carbon and energy source. The strain is able to grow on $o$-xylene but not on $m$ - and $p$-xylene. The inability of $\mathrm{R} 7$ strain to grow on the latter two compounds reinforced the hypothesis that the xylenes are metabolized at least by two different pathways [12]. Moreover, we have previously identified [22] the 2,3- and 3,4-dimethylphenols, as the main intermediates in the culture medium of R7 exposed to $o$-xylene, which are used by the strain as the only carbon and energy source, and not the corresponding dihydrodiol. Otherwise, in literature is reported by Kim et al. [10] that $o$-xylene is oxidized to the corresponding dihydrodiol. Moreover, Kim and co-authors also reported the direct formation of dimethylphenols in presence of $m$ - and $p$-xylenes by Rhodococcus sp. strain DK17. This suggests that alternative oxidation mechanisms of xylenes are possible [11]. Whether this is through the action of a dioxygenase, forming a dihydrodiol, which dehydrates to a phenolic intermediate, or through the action of a monooxygenase which can directly hydroxylate the aromatic ring (or a combination of the two steps), it remains to be investigated.

In this context, a genome-based approach was used to better understand the R7 peculiar $o$-xylene pathway. Consequently, we decided to investigate the role of some selected genes and to demonstrate their involvement in this catabolism (Fig. 8). As a first step we analyzed and clustered all the R7 genome oxygenase sequences generating two phylogenetic trees (Figs. 2 and 3).

From the dioxygenase tree analysis, we selected the AkbA1a dioxygenase coded by the $a k b A 1 a$ gene (included in the $a k b$ gene cluster), whose sequences are 90\% homologous to the sequence of the DK17 strain. In this paper, we demonstrate that the $a k b$ genes are induced by the presence of $o$-xylene supplied as the only carbon and energy source, both by RT-PCR/qPCR experiments and by selection of the R7-50 leaky mutant on $o$-xylene. RT-PCR analysis showed that $O$-xylene activated the transcription of the $a k b A 1 A 2$ genes coding for a $o$-xylene dioxygenase and the $a k b B$ gene coding for a dihydrodiol dehydrogenase, suggesting the dioxygenation route for the $o$-xylene oxidation. These data confirmed what was reported for DK17 strain [10].

However, these data are apparently in disagreement with what we observed in the R7 metabolic analysis [21], because we identified the 2,3- and 3,4-DMPs and no literature data supports enough that DMPs could derive from the dehydration of the corresponding dihydrodiol. Moreover, R7 strain was also able to grow on the corresponding 2,3- and 3,4-DMPs as the only carbon and energy source, suggesting an alternative pathway for the $o$-xylene oxidation through a monooxygenation. Since the focus of the present work was the identification of genes involved in the initial oxidation of $o$-xylene, we wanted to verify the formation mechanism of 2,3- and 3,4-DMPs from $o$-xylene. To support this hypothesis, we analyzed all the R7 monooxygenases/phenol hydroxylases sequences (Fig. 3). As a result, on the basis of sequence identities with other $o$-xylene monooxygenases/phenol hydroxylases, genome sequences of other bacteria, and comparison of the protein catalytic site, we found putative sequences that could be involved in $o$-xylene degradation. In clade number 4 , only one R7 protein sequence (PrmA) (P59) showed a significant amino acid identity with respect to reference $o$-xylene monooxygenases (like Toluene $o$-xylene Monooxygenase, ToMo). As the ToMo is the best known monooxygenase able to oxidize $o$-xylene with the formation of the corresponding DMPs, we hypothesized that PrmA could also be involved in this monooxygenation/hydroxylation. Thus, we investigated the role of the $\operatorname{prm} A$ gene in the $o$-xylene (or toluene) degradation by RT-PCR and quantitative real time RT-PCR experiments on R7 cells grown in presence of $o$-xylene. Results showed that 


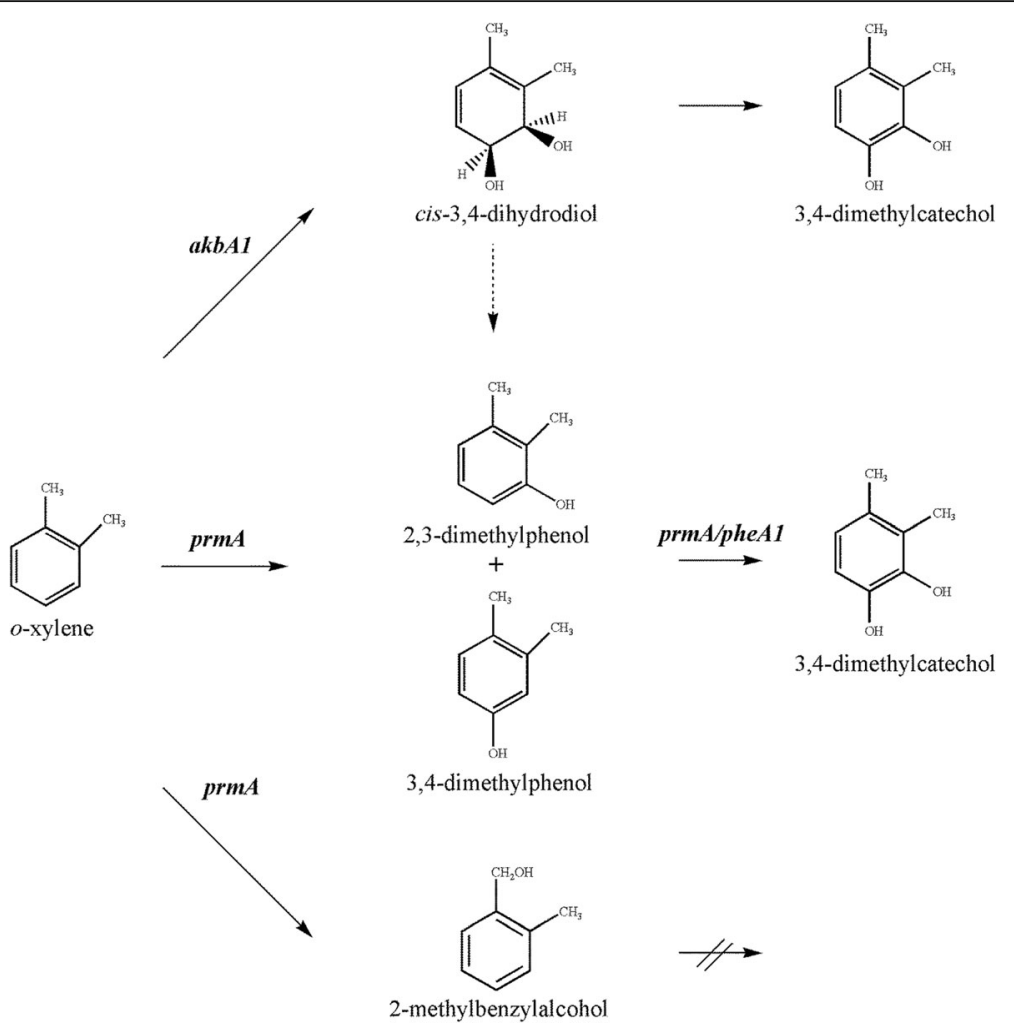

Fig. 8 Proposed metabolic pathways involved in o-xylene degradation in R. opacus R7. akbA1, o-xylene dioxygenase route; prmA, monooxygenase route; pheA1, phenol hydroxylase route. Predicted genes are listed in Table 1. Dashed arrow indicates a spontaneous dehydration

although the levels of the prmA gene increased little with respect to the growth on malate, it could be a first indication of the involvement of PrmA in this pathway. Then, the activity of the PrmACBD multicomponent monooxygenase was examined after the cloning of the corresponding genes in another Rhodococcus strain unable to use $o$-xylene like $R$. erythropolis AP. Results evidenced that $o$-xylene was slowly transformed in 3,4-DMP and 2-methylbenzylalcohol, that could be then metabolized by other monooxygenases/phenol hydroxylases. Indeed, R7 strain is able to grow also in presence of the DMPs when supplied as sole carbon and energy source. To support these data we have also looked for R7 monooxygenases/phenol hydroxylases. From R7 genome analysis, we identified three sets of two component phenol hydroxylases, constituted of an oxygenase component and a reductase component; two sets were allocated on the chromosome on two different regions, and the third one on the pPDG2 plasmid of R7, respectively. In this case, phe genes were selected for RT-PCR experiments to evaluate their involvement in $o$-xylene oxidation. In all the growth conditions utilized we observed an amplification of the corresponding genes. The pheAla encoding for the PheAla (P115) was also tested in the quantitative real time RT-PCR on R7 cells grown in presence of $o$-xylene, toluene, 2,3-DMP and malate. Results showed a significant increase of pheA1a gene transcriptional levels during the growth on 2,3-DMP in respect to the growth on malate. This suggested that the phe genes could be involved in the second step of $o$-xylene degradation.

R7 strain showed a substrate versatility in respect to different substituted phenols, including 2,3-DMP and 3,4-DMP. This substrate versatility could likely be the result of gene redundancy and the presence of several phenol hydroxylase (iso)enzymes. These data are in accordance with literature, where it is reported that: three phenol hydroxylases in $R$. opacus $\mathrm{B} 4$, four in $R$. opacus M213, five in $R$. opacus PD630 and four in the reference strain $R$. jostii RHA1 have evident activities and expression profiles for this class of enzymes in these bacteria [26].

Thus, considering such metabolic diversity of R7 strain, we would deduce that, although the $a k b$ genes are the specific activated genes for $o$-xylene degradation, other genes such as prm genes can induce an increase of levels of phenols that can converge towards the phenol oxidation route.

The co-activation of multiple oxygenases could contribute to such strategy in these kinds of bacteria particularly resistant to environmental stress. Indeed, it has been demonstrated [42] that large genome with multiple 
broad-specificity catabolic enzymes such as those reported in RHA1 strain could have a competitive advantage in environmental changing soil conditions.

\section{Conclusions}

In conclusion, in this paper we demonstrate that $R$. opacus R7 is able to degrade $o$-xylene by the activation of the $a k b$ genes leading to the production of the corresponding dihydrodiol. Likewise, the redundancy of sequences encoding for several monooxygenases/phenol hydroxylases, supports the involvement of other genes that can induce an increase of levels of phenols that can converge towards the phenol oxidation route.

The activation of multiple converging oxygenase systems represents a strategy in bacteria of Rhodococcus genus to degrade a wide range of recalcitrant compounds and to persist in severely contaminated environments.

\section{Methods}

\section{Bacterial strain and growth conditions}

The bacterial strain used in this study is R. opacus R7, isolated for its ability to grow on naphthalene and $o$-xylene as previously described [21] (deposited to the Institute Pasteur Collection, CIP identification number 107348). The strain was grown at $30^{\circ} \mathrm{C}$ in $\mathrm{M} 9$ mineral medium [43], supplemented with the following carbon sources as only carbon and energy source: $o$-xylene, toluene (final concentration of $1 \mathrm{~g} / \mathrm{l}$ ) or 2,3-dimethylphenol, 3,4-dimethylphenol (final concentration of 5-10 mM), or 2-dimethylbenzylalcohol, 3-dimethylbenzylalcohol or malate (final concentration of $10 \mathrm{mM}$ ). The $R$. opacus R7 growth on $o$-xylene, toluene, took place on M9 mineral medium in an atmosphere saturated with these aromatic compounds in a sealed system. The mutant R7-50 strain used in this paper was grown in the same conditions utilized for the wild type R7 strain.

Rhodococcus erythropolis AP, isolated in our laboratory (CIP 110799) for its ability to grow on diesel fuel, was maintained on M9 mineral medium in a saturated atmosphere of diesel fuel at $30{ }^{\circ} \mathrm{C}$.

\section{Bioinformatic analysis: Nucleotide sequence \\ determination and protein sequence analysis}

The preliminary annotation of $R$. opacus R7 genome sequences was performed using the RAST (Rapid Annotation using Subsystem Technology) service [44].

BLASTn tool [45] of NCBI pipeline was used to determine nucleotide sequence homology and to make manual curation.

$R$. opacus R7 putative gene clusters for $o$-xylene catabolism were identified on chromosome and megaplasmids using BLAST tool and Clustal Omega [46].

$R$. opacus $\mathrm{R} 7$ protein sequences were preliminary annotated using the RAST that allowed to identify potential monooxygenases/hydroxylases and dioxygenases using text string searching.

These sequences annotated as monooxygenases/hydroxylases and dioxygenases were aligned separately against PDB (RCSB Protein Data Bank) database to identify reference sequences. Reference proteins were selected on the basis of the highest similarity or literature data. If no match was identify against PDB database, the same procedure was applied using BLASTp of NCBI pipeline.

Afterwards, the identified reference sequences were aligned against R7 genome using the NCBI pipeline in order to verify to have considered all R7 putative monooxygenases/hydroxylases and dioxygenases.

The retrieved sequences were aligned using the multiple sequence alignment (MSA) tool of Clustal Omega program using the default parameters (neighbour joining method, the Gonnet transition matrix, gap opening penalty of 6 bits, maintain gaps with an extension of 1 bit, used bed-like clustering during subsequent iterations, and zero number of combined iterations).

For each group of oxygenases, the MSA was used for the cluster analysis inferred using the maximum likelihood (ML) method selected from the package MEGA version 6 [47]. The following parameters were used: JTT matrix, used all sites and gamma distribution of mutation rates with gamma optimized to 2 . As a test of inferred phylogeny, 100 bootstrap replicates were used.

The resulting groups allowed to define two different trees, one for all the dioxygenases and one for all the monooxygenases/hydroxylases of R7 showing clades with putative functions identified by InterPro/UniProt databases.

\section{Preparation, analysis, and DNA manipulation}

Total DNA from $R$. opacus R7 was extracted according to method reported by Di Gennaro et al. [22]. The extract was precipitated by 0.1 volume of $3 \mathrm{M}$ sodium acetate and after centrifugation, the DNA was isolated and purified. Standard methods of DNA manipulation were used in this work [43]. For the recovery and purification of DNA fragments from agarose, Extraction Kits by Nachery and Nagel (Fisher Scientific, Germany) were used. Amplification of fragment containing genes target was achieved by PCR performed using primers designed ad hoc (Additional file 3: Table S3 and Additional file 4: Table S4) to amplify the sequences of interest.

\section{RNA extraction and RT-PCR, quantitative real-time RT-PCR (qPCR)}

Total RNA was extracted from bacterial cultures of $R$. opacus $\mathrm{R} 7(100 \mathrm{ml})$ grown at $30{ }^{\circ} \mathrm{C}$ on $\mathrm{M} 9$ mineral medium supplemented with different substrates supplied (as described above) as the only carbon and energy source: $o$-xylene, toluene at the concentration of $1 \mathrm{~g} / \mathrm{l}, 2,3$-dimethylphenol and 3,4-dimethylphenol at 
the concentration of $5-10 \mathrm{mM}$ and $10 \mathrm{mM}$ malate used as reference.

RNA extraction protocol was performed using the RNA-Total RNA Mobio Isolation Kit (Qiagen Italia, Italy) according to the manufacturer's instructions and at the end the DNase treatment was performed. Reverse transcription was performed with iScript cDNA Synthesis kit (BIO-RAD, Italy) to obtain the corresponding cDNAs. For the cDNA synthesis 200 ng of total RNA was reverse-transcribed as follows: after denaturation for $5 \mathrm{~min}$ at $25^{\circ} \mathrm{C}$, reverse transcription was performed for $1 \mathrm{~h}$ at $42{ }^{\circ} \mathrm{C}$ and then $5 \mathrm{~min}$ of elongation at $85^{\circ} \mathrm{C}$.

RT-PCR experiments were performed by amplification of the cDNA samples, each in $25-\mu \mathrm{l}$ PCR volume containing $2 \mu \mathrm{l}$ of the reverse-transcribed RNA samples.

Amplifications of the akbA1A2, akbB, akbC, prmA (P59), pheA1a (P115), pheA3a (P143) genes and 16S rDNA were performed using $2.5 \mathrm{U} / \mu \mathrm{l}$ of Long Range DNA Rabbit Polymerase (Eppendorf, Germany).

Thermo cycling conditions were as follows: $3 \mathrm{~min}$ at $95{ }^{\circ} \mathrm{C}, 95{ }^{\circ} \mathrm{C}$ for $30 \mathrm{~s}$, specific $\mathrm{T}_{\mathrm{m}}$ for $45 \mathrm{~s}, 72{ }^{\circ} \mathrm{C}$ for $4 \mathrm{~min}$, for 35 cycles; and $72{ }^{\circ} \mathrm{C}$ for $3 \mathrm{~min}$. Amplification of $16 \mathrm{~S}$ rDNA was performed using the universal bacterial primers $27 \mathrm{f}$ and $1495 \mathrm{r}$ as described in Di Gennaro et al. [21]. The internal housekeeping gene (16S rDNA) was used as reference to evaluate relative differences in the integrity of individual RNA samples.

Quantitative real-time Reverse Transcriptase-PCR (qPCR) analyses were performed on the same samples used for RT-PCR. The reverse-transcribed samples were amplified using the StepOnePlus Real-Time PCR System (Applied Biosystem, Italy). Each 10- $\mu$ l qPCR volume contained $4.4 \mu \mathrm{l}$ of the reverse-transcribed RNA samples, $5 \mu \mathrm{l}$ of PowerUp SYBR Green Master Mix (Applied Biosystem, Thermo Scientific, Italy), and $300 \mathrm{nM}$ of each primer, listed in Additional file 3: Table S3. Thermocycling conditions were as follows: $30 \mathrm{~s}$ at $95{ }^{\circ} \mathrm{C}$, followed by 40 cycles of $5 \mathrm{~s}$ at $95^{\circ} \mathrm{C}, 10 \mathrm{~s}$ at $60^{\circ}$ $\mathrm{C}$ and $45 \mathrm{~s}$ at $72{ }^{\circ} \mathrm{C}$ and one cycle $15 \mathrm{~s}$ at $95{ }^{\circ} \mathrm{C}, 1 \mathrm{~min}$ at $60{ }^{\circ} \mathrm{C}$ and $15 \mathrm{~s}$ at $60{ }^{\circ} \mathrm{C}$. Expression of the housekeeping gene, $16 \mathrm{~S}$ rDNA, was used as reference gene to normalize tested genes in $R$. opacus $\mathrm{R} 7$. The $\Delta \Delta \mathrm{Ct}$ method with $16 \mathrm{~S}$ rDNA as reference gene was used to determine relative abundance of target transcripts in respect to malate as control. Data are expressed as mean \pm standard deviation derived from at least three independent experiments.

In order to exclude DNA contamination, negative controls were performed by omitting the reverse transcriptase in RT-PCR experiments, which were conducted with the same temperature program and the same primer sets for 35 cycles of amplification.

The primers used in the RT-PCR analysis and qPCR are described in Additional file 3: Table S3.

\section{Mutant preparation \\ Transposon-induced mutagenesis in $R$. opacus $R 7$ using IS1415 (pTNR-TA vector)}

Plasmid pTNR-TA [48] was transferred into $R$. opacus strain R7 by electroporation as described by Treadway et al. [49], using a Gene Pulser II (BIO-RAD, Italy) set at $2.50 \mathrm{kV}, 600 \Omega, 25 \mu \mathrm{F}$ in presence of maximum $1 \mu \mathrm{g}$ DNA in a $2 \mathrm{~mm}$-gap electro-cuvette (BIO-RAD, Italy). Afterwards, the electroporation mixture was suspended in $2.5 \mathrm{ml} \mathrm{LB}$ and it was incubated for $4 \mathrm{~h}$ at $30^{\circ} \mathrm{C}$ under shaking. Cells were plated on Luria-Bertani (LB) supplemented with $12.5 \mu \mathrm{g} / \mathrm{ml}$ thiostrepton and they were grown at $30{ }^{\circ} \mathrm{C}$ for 5 days to select thiostrepton-resistant cells. Transposon-induced mutants were transferred to M9 mineral medium agar plates with $12.5 \mu \mathrm{g} / \mathrm{ml}$ thiostrepton and $10 \mathrm{mM}$ malate.

The transposon-induced mutants obtained were tested on M9 mineral medium agar plates with the following carbon sources as the only carbon and energy source at the final concentration of $1 \mathrm{~g} / \mathrm{l}: \quad o$-xylene; toluene; 2,3-dimethylphenol and 3,4-dimethylphenol (5-10 mM); 2 dimethylbenzylalcohol.

\section{Analysis of pTNR-TA insertion sites}

The genomic DNA of each transposon-induced mutant was extracted and the Two-Step gene walking PCR method was applied [50]. Insertions of IS1415 into the genomes of these mutants were confirmed by PCR using primers reported in Additional file 4: Table S4. Genomic DNA of the wild type strain was used as a negative control. Homology searches of the interrupted DNA sequences from mutants were conducted by BLAST (http://blast.ncbi.nlm.nih.gov/Blast.cgi) [45].

\section{Construction of the recombinant strain $R$. erythropolis AP (pTipQC2-prmACBD-R7)}

The prmACBD gene cluster was ligated as NdeI/HindIII fragment into a shuttle-vector E. coli-Rhodococcus, pTipQC2 [51]. The ligation mixture was used to transform E. coli $\mathrm{DH} 5 \alpha$ by electroporation with standard procedures [52] and the recombinant clones were selected on LB agar supplemented with ampicillin $(100 \mu \mathrm{g} / \mathrm{ml})$ at $37^{\circ} \mathrm{C}$. Ampicillin-resistant clones were selected and the recombinant plasmid (pTipQC2-pr$m A C B D-\mathrm{R} 7)$ was isolated. The same recombinant plasmid was used to transform $R$. erythropolis strain AP by electroporation according to Zampolli et al. [23]. Immediately after electroporation, $2.5 \mathrm{ml}$ recovery broth (LB medium with $1.8 \%$ sucrose) were added and cells were incubated at $30{ }^{\circ} \mathrm{C}$ for $4 \mathrm{~h}$. Cells were plated on LB supplemented with chloramphenicol $50 \mu \mathrm{g} / \mathrm{ml}$ and grown at $30{ }^{\circ} \mathrm{C}$ for $3-4$ days. Recombinant strain $R$. erythropolis AP (pTipQC2-prmACBD-R7) was used for bioconversion experiments in presence of $o$-xylene to 
evaluate the activity of the prmACBD system in comparison to the activity of the wild type strain.

\section{Bioconversion experiments of the recombinant strain $R$. erythropolis AP (pTipQC2-prmACBD-R7) in presence of o- xylene}

Cells of $R$. erythropolis AP (pTipQC2-prmACBD-R7) were grown in 500-mL Erlenmeyer flasks containing $100 \mathrm{~mL}$ of $\mathrm{LB}$ at $30{ }^{\circ} \mathrm{C}$. When the culture reached the O.D.600 of 0.6 , they were induced with thiostrepton. After overnight growth, the cells were collected by centrifugation for $10 \mathrm{~min}$ at 20,000 g, washed and re-suspended in the mineral medium M9 to have final O.D.600 of 1.

Bioconversion experiments were performed in a biphasic system with $o$-xylene $(1 \mathrm{~g} / \mathrm{l})$ dissolved in isoctan at $20 \%$ of the final volume of the culture. At fixed times, $2 \mathrm{~h}$, $4 \mathrm{~h}, 6 \mathrm{~h}$, and $24 \mathrm{~h}$, a flask was sacrificed to determine the metabolites produced during growth on $o$-xylene. It occurred by HPLC analysis after acidification with $\mathrm{H}_{2} \mathrm{SO}_{4}$. After settling of the suspension, the aqueous phase was drawn from the organic phase, stripped under a gentle stream of nitrogen, resuspended in order to concentrate each culture 1:20 and filtered with $0.45 \mu \mathrm{m}$ filters for HPLC analysis.

\section{Analytical methods}

HPLC analyses were performed with a Waters 600E delivery system (Waters Corporation, Milford, MA, USA) equipped with a Waters 486 UV-Vis detector and a Waters reverse-phase $\mu$ Bondapak $3.9 \times 300 \mathrm{~mm} \mathrm{C18}$ column. The mobile phase was acetonitrile:water (50:50) at a flow rate of $1 \mathrm{~mL} / \mathrm{min}$ in isocratic conditions. The detection was carried out at $254 \mathrm{~nm}$ and the retention times of the identified peaks were compared with those of authentic compounds. Co-elution experiments were also performed in which the culture broth samples were supplemented with authentic compounds. In these conditions, the retention times were $4.33 \mathrm{~min}$ for 2-methylbenzylalcohol, $6.39 \mathrm{~min}$ for 2,3-dimethylphenol, and 5.79 min for 3,4-dimethylphenol.

\section{Additional files}

Additional file 1: Table S1. Sequences used to generate dioxygenase tree. (DOCX $25 \mathrm{~kb}$ )

Additional file 2: Table S2. Sequences used to generate monooxygenase tree. (DOCX $44 \mathrm{~kb}$ )

Additional file 3: Table S3. List of utilized oligos. (DOCX $15 \mathrm{~kb}$ ) Additional file 4: Table S4. List of utilized oligos for transposon identification. (DOCX 13 kb)

\section{Abbreviations}

2,3-DMP: 2,3-dimethyl phenol; 3,4-DMP: 3,4-dimethyl phenol; BLAST: Basic Local Alignment Search Tool; BTEX: benzene, toluene, ethylbenzene and xylenes; cDNA: Complementary Deoxyribonucleic Acid; DMPs: dimethyl phenols; HP: hypothetical protein; HPLC: High-Performance Liquid Chromatography; LB: Luria-Bertani; NCBI: National Center for Biotechnology Information; O.D.600: Optical Density at 600 nm; ORFs: Open Reading Frames; PAHs: polycyclic aromatic hydrocarbons; PCBs: polychlorinated biphenyls; PDB: RCSB Protein Data Bank; qPCR: quantitative real time RT-PCR; RAST: Rapid Annotation using Subsystem Technology; RT-PCR: Reverse Transcriptase Polymerase Chain Reaction; ToMo/PH: Toluene o-xylene Monooxygenase/Phenol Hydroxylase

\section{Acknowledgments}

We would like to thank the Department of Organic Chemistry of the University of Milano for the support in the analytical instrument procedures. We thank also our students Matteo Uggeri and Delia Valsecchi.

\section{Funding}

We thanks CNR for supporting our research with the Project Interomics and the Italian Ministry of University.

\section{Availability of data and materials}

The datasets analysed in this study are available at DDBJ/EMBL/GenBank under the Accession Numbers CP008947, CP008948, CP008949, CP008950, CP008951, CP008952 for R. opacus R7.

All data generated during this study are included in this article and its additional files.

\section{Authors' contributions}

PDG and LM planned the experiments. ADC, JZ, performed molecular experiments, PDU and AO performed bioinformatic analysis, GS performed chemical analysis. GS and AS analysed and interpreted the data. PDG, JZ and GS wrote the manuscript. All the authors reviewed the manuscript. All authors read and approved the final manuscript.

Ethics approval and consent to participate

All procedures performed in this study were compliance with Ethical Standards. This article does not contain any studies with human participants or animals performed by any of the authors.

Consent for publication

Not Applicable.

Competing interests

The authors declare that they have competing interests.

\section{Publisher's Note}

Springer Nature remains neutral with regard to jurisdictional claims in published maps and institutional affiliations.

\section{Author details}

${ }^{1}$ Department of Biotechnology and Biosciences, University of Milano-Bicocca, Piazza della Scienza 2, 20126 Milan, Italy. ${ }^{2}$ ITB, CNR, via Fratelli Cervi 19, 20133 Segrate, Milan, Italy. ${ }^{3}$ Department of Chemistry, University of Milano, via Golgi 19, 20133 Milan, Italy. ${ }^{4}$ Department of Molecular Microbiology and Biotechnology, Westfälische Wilhelms-Universität Münster, Münster, Germany. ${ }^{5}$ Environmental Sciences Department, King Abdulaziz University, Jeddah, Saudi Arabia.

Received: 26 March 2018 Accepted: 30 July 2018

Published online: 06 August 2018

References

1. Barbieri P, Palladino L, Di Gennaro P, Galli E. Alternative pathways for oxylene or $m$-xylene and $p$-xylene degradation in Pseudomonas stutzeri strain. Biodegradation. 1993:4:71-80.

2. Kim D, Kim YS, Kim SK, Kim SW, Zylstra GJ, Kim YM, et al. Monocyclic aromatic hydrocarbon degradation by Rhodococcus sp. strain DK17. Appl Environ Microbiol. 2002;6:3270-8.

3. Galli E, Barbieri P, Bestetti G. Potential of Pseudomonas in the degradation of methylbenzenes. In: Galli E, Silver S, Witholt E, editors. Pseudomonas: molecular biology and biotechnology. Washington, DC: American Society for Microbiology; 1992. p. 268-76. 
4. Harayama S, Kok M, Neidle EL. Functional and evolutionary relationships among diverse oxygenases. Annu Rev Microbiol. 1992;46:565-601.

5. Williams PA, Sayers JR. The evolution of pathways for aromatic hydrocarbon oxidation in Pseudomonas. Biodegradation. 1994;5:195-217.

6. Jindrovà $E$, Chocovà $M$, Demnerovà K, Brenner V. Bacterial aerobic degradation of benzene, toluene, ethylbenzene and xylene. Folia Microbiol. 2002:47:83-93.

7. Schraa G, Bethe BM, van Neerven ARW, Van Den Tweel WJJ, Van Der Wende E, Zehnder AJB. Degradation of 1,2-dimethylbenzene by Corynebacterium strain C125. Antoine van Leewenhock. 1987;53:159-70.

8. Bickerdike SR, Holt RA, Stephens GM. Evidence for metabolism of o-xylene by simultaneous ring and methyl group oxidation in a new soil isolate. Microbiology. 1997;143:2321-9.

9. Vardar G, Wood TK. Protein engineering of toluene-o-xylene monooxygenase from Pseudomonas stutzeri OX1 for synthesizing 4methylresorcinol, methylhydroquinone, and pyrogallol. Appl Environ Microbiol. 2004;70:3253-62.

10. Kim D, Chae JC, Zylstra GJ, Kim YS, Kim SK, Nam MH, et al. Identification of a novel dioxygenase involved in metabolism of o-xylene, toluene, and ethylbenzene by Rhodococcus sp. strain DK17. Appl Environ Microbiol. 2004; 70:7086-92.

11. Kim D, Choi KY, Yoo M, Choi JN, Lee CH, Zylstra GJ, et al. Benzylic and aryl hydroxylations of $m$-xylene by o-xylene dioxygenase from Rhodococcus sp. strain DK17. Appl Microbiol Biotechnol. 2010;86:1841-7.

12. Kim D, Kim Y-S, Jung JW, Zylstra J, Kim YM, Kim S-K, et al. Regioselective oxidation of xylene isomers by Rhodococcus sp. strain DK17. FEMS Microbiol Lett. 2003;223:211-4.

13. Kukor JJ, Olsen RH. Molecular cloning, characterization and regulation of a Pseudomonas pikettii PKO1 gene encoding phenol hydroxylase and expression of the gene in Pseudomonas aeruginosa PA01c. J Bacteriol. 1990; 172:4624-30.

14. Martìnkovà L, Uhnàkovà B, Pàtek M, Nesvera J, Kren V. Biodegradation potential of the genus Rhodococcus. Environ Int. 2009;35:162-77.

15. Alvarez HM. Central metabolism of the species of the genus Rhodococcus. In: Alvarez HM, editor. Biology of Rhodococcus. Berlin Heidelberg: Springer; 2010. p. 91-108.

16. Larkin MJ, Kulakov LA, Allen CCR. Genomes and plasmids in Rhodococcus. In: Alvarez HM, editor. Biology of Rhodococcus. Berlin, Heidelberg: Springer; 2010. p. 73-90.

17. McLeod MP, Warren RL, Hsiao WW, Araki N, Myhre M, Fernandes C, et al. The complete genome of Rhodococcus sp. RHA1 provides insights into a catabolic powerhouse. Proc Natl Acad Sci U S A. 2006;103:15582-7.

18. Seto M, Masai E, Ida M, Hatta T, Kimbara K, Fukuda M, et al. Multiple polychlorinated biphenyl transformation systems in the gram-positive bacterium Rhodococcus sp. strain RHA1. Appl Environ Microbiol. 1995;61:4510-3.

19. Sakai M, Miyauchi K, Kato N, Masai E, Fukuda M. 2-Hydroxypenta-2,4-dienoate metabolic pathway genes in a strong polychlorinated biphenyl degrader, Rhodococcus sp. strain RHA1. Appl Environ Microbiol. 2003;69:427-33.

20. Kesseler M, Dabbs ER, Averhoff B, Gottschalk G. Studies on the isopropylbenzene 2,3-dioxygenase and the 3-isopropylcatechol 2,3dioxygenase genes encoded by the linear plasmid of Rhodococcus erythropolis BD2. Microbiology. 1996;142:3241-51.

21. Di Gennaro P, Rescalli E, Galli E, Sello G, Bestetti G. Characterization of Rhodococcus opacus R7, a strain able to degradate naphthalene and oxylene isolated from polycyclic aromatic hydrocarbon-contaminated soil. Res Microbiol. 2001;152:641-51.

22. Di Gennaro P, Terreni P, Masi G, Botti S, De Ferra F, Bestetti G. Identification and characterization of genes involved in naphthalene degradation in Rhodococcus opacus R7. Appl Microbiol Biotechnol. 2010;87:297-308.

23. Zampolli J, Collina E, Lasagni M, Di Gennaro P. Biodegradation of variable-chain-length $n$-alkanes in Rhodococcus opacus R7 and the involvement of an alkane hydroxylase system in the metabolism. AMB Express. 2014;4:73

24. Orro A, Cappelletti M, D'Ursi P, Milanesi L, Di Canito A, Zampolli J, et al. Genome and phenotype microarray analyses of Rhodococcus sp. BCP1 and Rhodococcus opacus R7: genetic determinants and metabolic abilities with environmental relevance. Plos One. 2015; https://doi.org/10.1371/journal. pone.0139467.

25. Gonçalves ER, Hara H, Miyazawa D, Davies JE, Eltid LD, Mohn WW. Transcriptomic assessment of isozymes in the biphenyl pathway of Rhodococcus sp. strain RHA1. Appl Environ Microbiol. 2006;72:6183-93.
26. Gröning JAD, Eulberg D, Tischler D, Kaschabek SR, Schlömann M. Gene redundancy of two-component (chloro)phenol hydroxylases in Rhodococcus opacus 1CP. FEMS Microbiol Lett. 2014;361:68-75.

27. Bertoni G, Martino M, Galli E, Barbieri P. Analysis of the gene cluster encoding toluene/o-xylene monooxygenase from Pseudomonas stutzeri OX1. Appl Environ Microbiol. 1998;64:3626-32.

28. Cafaro V, Notomista E, Capasso P, Di Donato A. Regiospecificity of two multicomponent monooxygenases from Pseudomonas stutzeri OX1: molecular basis for catabolic adaptation of this microorganism to methylated aromatic compounds. Appl Environ Microbiol. 2005;71:4736-43.

29. Notomista E, Lahm A, Di Donato A, Tramontano A. Evolution of bacterial and archaeal multicomponent monooxygenases. J Mol Evol. 2003;56:435-45.

30. Leahy JG, Batchelor PJ, Morcomb SM. Evolution of the soluble diiron monooxygenases. FEMS Microbiol Rev. 2003;27:449-79.

31. Yachnin BJ, McEvoy MB, MacCuish RJD, Morley KL, Lau PCK, Berghuis AM. Lactone-bound structures of cyclohexanone monooxygenase provide insight into the stereochemistry of catalysis. ACS Chem Biol. 2014:9:2843-51.

32. Jensen CN, Ali ST, Allen MJ, Grogan G. Exploring nicotinamide cofactor promiscuity in $\mathrm{NAD}(\mathrm{P}) \mathrm{H}$-dependent flavin containing monooxygenases (FMOs) using natural variation within the phosphate binding loop. Structure and activity of FMOs from Cellvibrio sp. BR and Pseudomonas stutzeri NF13. J Mol Catal B Enzym. 2014;109:191-8.

33. Montersino S, van Berkel WJH. Functional annotation and characterization of 3-hydroxybenzoate 6-hydroxylase from Rhodococcus jostii RHA1. Biochim Biophys Acta. 1824;2012:433-42.

34. Bernhardt R, Urlacher VB. Cytochromes P450 as promising catalysts for biotechnological application: chances and limitations. Appl Microbiol Biotechnol. 2014;98:6185-203.

35. Uetz T, Schneider R, Mario S, Egli T. Purification and characterization of a two-component monooxygenase that hydroxylates nitrilotriacetate from "Chelatobacter" strain ATCC 29600. J Bacteriol. 1992;174:1179-88.

36. Eichhorn E, Davey CA, Sargent DF, Leisinger T, Richmond TJ. Crystal structure of Escherichia coli alkanesulfonate monooxygenase SsuD. J Mol Biol. 2002:324:457-68.

37. Gin P, Hsu AY, Rothman SC, Jonassen T, Lee PT, Tzagoloff A, Clarke CF. The Saccharomyces cerevisiae COQ6 gene encodes a mitochondrial flavindependent monooxygenase required for coenzyme Q biosynthesis. J Biol Chem. 2003:278:5308-25316.

38. Kim D, Chae JC, Zylstra GJ, Sohn HY, Kwon GS, Kim E. Identification of twocomponent regulatory genes involved in 0 -xylene degradation by Rhodococcus sp. strain DK17. J Microbiol. 2005;43:49-53.

39. Sharp JO, Sales CM, LeBlanc JC, Liu J, Wood TK, Eltis LD, et al. An inducible propane monooxygenase is responsible for $\mathrm{N}$-nitrosodimethylamine degradation by Rhodococcus sp. strain RHA1. Appl Environ Microbiol. 2007; 73:6930-8.

40. Patrauchan MA, Florizone C, Eapen S, Gòmez-Gil L, Sethuaman B, Fukuda M, et al. Roles of ring-hydroxylating dioxygenases in styrene and benzene catabolism in Rhodococcus jostii RHA1. J Bacteriol. 2007;190:37-47.

41. Pathak A, Chauhan A, Blom J, Indest KJ, Jung CM, Stothard P, et al. Comparative genomics and metabolic analysis reveals peculiar characteristics of Rhodococcus opacus strain M213 particularly for naphthalene degradation. PLoS One. 2016;17:1-32.

42. lino T, Wang $Y$, Miyauchi $K$, Kasai D, Masai E, Fujii T, et al. Specific gene responses of Rhodococcus jostii RHA1 during growth in soil. Appl Environ Microbiol. 2012;78:6954-62.

43. Maniatis T, Fritsch EF, Sambrook J. Molecular cloning: a laboratory manual. New York: Cold Spring Harbor Laboratory, Cold Spring Harbor; 1982.

44. Aziz RK, Bartels D, Best AA, DeJongh M, Disz T, Edwards RA, et al. The RAST server: rapid annotations using subsystems technology. BMC Genomics. 2008;9:75.

45. Altschul SF, Gish W, Miller W, Myers EW, Lipman DJ. Basic local alignment search tool. J Mol Biol. 1990;215:403-10.

46. Thompson JD, Higgins DG, Gibson TJ. CLUSTAL W: improving the sensitivity of progressive multiple sequence alignment through sequence weighting, position-specific gap penalties and weight matrix choice. Nucleic Acids Res. 1994:22:4673-80.

47. Tamura K, Stecher G, Peterson D, Filipski A, Kumar S. MEGA6: molecular evolutionary genetics analysis version 6.0. Mol Biol Evol. 2013;30:2725-9.

48. Sallam Kl, Mitani Y, Tamura T. Construction of random transposition mutagenesis system in Rhodococcus erythropolis using IS1415. J Biotechnol. 2006;121:13-22 
49. Treadway SL, Yanagimachi KS, Lankenau E, Lessard PA, Stephanopoulos G, Sinskey AJ. Isolation and characterization of indene bioconversion genes from Rhodococcus strain 124. Appl Microbiol Biotechnol. 1999;51:786-93.

50. Pilhofer M, Bauer AP, Schrallhammer M, Richter L, Ludwig W, Schleifer K-H, et al. Characterization of bacterial operons consisting of two tubulins and a kinesin-like gene by the novel two-step gene walking method. Nucleic Acids Res. 2007; https://doi.org/10.1093/nar/gkm836.

51. Nakashima N, Tamura T. A novel system for expressing recombinant proteins over a wide temperature range from 4 to $35^{\circ} \mathrm{C}$. Biotechnol Bioeng. 2004;86:136-48.

52. Sambrook J, Russell DW. Molecular cloning: a laboratory manual. New York: Cold Spring Harbor Laboratory, Cold Spring Harbor; 1989.

Ready to submit your research? Choose BMC and benefit from:

- fast, convenient online submission

- thorough peer review by experienced researchers in your field

- rapid publication on acceptance

- support for research data, including large and complex data types

- gold Open Access which fosters wider collaboration and increased citations

- maximum visibility for your research: over $100 \mathrm{M}$ website views per year

At $\mathrm{BMC}$, research is always in progress.

Learn more biomedcentral.com/submissions 